\title{
Prion peptide-mediated calcium level alteration governs neuronal cell damage through AMPK-autophagy flux
}

\author{
Ji-Hong Moon and Sang-Youel Park (D)
}

\begin{abstract}
Background: The distinctive molecular structure of the prion protein, PrPsc, is established only in mammals with infectious prion diseases. Prion protein characterizes either the transmissible pathogen itself or a primary constituent of the disease. Our report suggested that prion protein-mediated neuronal cell death is triggered by the autophagy flux. However, the alteration of intracellular calcium levels, AMPK activity in prion models has not been described. This study is focused on the effect of the changes in intracellular calcium levels on AMPK autophagy flux pathway and PrP (106-126)-induced neurotoxicity.

Methods: Western blot and Immunocytochemistry was used to detect AMPK and autophagy-related protein expression. Flow cytometry and a TdT-mediated biotin-16-dUTP nick-end labeling (TUNEL) assay were used to detect the percentage of apoptotic cells. Calcium measurement was employed using fluo-4 by confocal microscope.
\end{abstract}

Results: We examined the effect of calcium homeostasis alterations induced by human prion peptide on the autophagy flux in neuronal cells. Treatment with human prion peptide increased the intracellular calcium concentration and induced cell death in primary neurons as well as in a neuronal cell line. Using pharmacological inhibitors, we showed that the L-type calcium channel is involved in the cellular entry of calcium ions. Inhibition of calcium uptake prevented autophagic cell death and reduction in AMP-activated protein kinase (AMPK) activity induced by human prion peptide.

Conclusion: Our data demonstrated that prion peptide-mediated calcium inflow plays a pivotal role in prion peptide-induced autophagic cell death, and reduction in AMPK activity in neurons. Altogether, our results suggest that calcium influx might play a critical role in neurodegenerative diseases, including prion diseases.

Keywords: Calcium, Prion, Autophagy flux, Neurodegeneration, AMPK

\section{Background}

Protein accumulation in the brain is related to the pathogenesis of various neurodegenerative diseases, such as Parkinson's disease, Alzheimer's disease, as well as prion diseases [1]. Although prion disease is intermittent, it is lethal due to the non-availability of medical

\footnotetext{
* Correspondence: sypark@jbnu.ac.kr

Biosafety Research Institute, College of Veterinary Medicine, Jeonbuk National University, Gobong ro, Iksan, Jeonbuk 54596, South Korea
}

treatments to stop or interrupt the disease progression. Furthermore, prion transmission is a dangerous menace to community health due to the high resistance of prion proteins to standard disinfection methods [2]. The normal cellular prion protein $(\mathrm{PrPc})$ is converted to scrapie-associated prion protein (PrPsc) through progressive changes involving the conversion of its $\alpha$-helical domains to $\beta$-sheets [3]. These diseases share a general mechanism that includes structural modification of the

(c) The Author(s). 2020 Open Access This article is licensed under a Creative Commons Attribution 4.0 International License, which permits use, sharing, adaptation, distribution and reproduction in any medium or format, as long as you give appropriate credit to the original author(s) and the source, provide a link to the Creative Commons licence, and indicate if changes were made. The images or other third party material in this article are included in the article's Creative Commons licence, unless indicated otherwise in a credit line to the material. If material is not included in the article's Creative Commons licence and your intended use is not permitted by statutory regulation or exceeds the permitted use, you will need to obtain permission directly from the copyright holder. To view a copy of this licence, visit http://creativecommons.org/licenses/by/4.0/. The Creative Commons Public Domain Dedication waiver (http://creativecommons.org/publicdomain/zero/1.0/) applies to the data made available in this article, unless otherwise stated in a credit line to the data. 
disease-causing protein, leading to the generation of selfreplicating particles and subsequent pathogenesis within the central nervous system (CNS) [4]. However, it remains unclear whether scrapie pathogenesis associated neurotoxicity is through PrPc or other mechanisms [5]. Human prion peptide corresponding to amino acid residues 106-126, can form fibrils in vitro and is noxious to hippocampal neurons [6]. It might be possible that the toxic form of PrP is created directly from PrPc or as a predecessor to pathological PrP [7].

Prion diseases are correlated with the deregulation of autophagy flux, as evidenced by the deposition of massive autophagic vacuoles in a hamster model of scrapie [8]. These autophagic vacuoles often enlarge in size and increase in number as neurons age, ultimately occupying the whole neurites [9]. Autophagic cell death, also known as programmed cell death II, is involved in the intracellular process that results in the dilapidation of cytosolic constituents inside the lysosomes [10]. The function of the lysosome is well-characterized in programmed cell death, although its exact role remains blurred [11]. Recent studies investigating the degradation of PrPsc revealed that the lysosome performs an imperative role in prion protein degradation and autophagy flux may be the main mechanism of PrPsc transport to the lysosomes [12-14]. Based on these observations, the authors suggested that autophagy flux might be beneficial in various diseases. $\mathrm{Xu}$ et al. advocated that the macro-autophagic system is stimulated in the scrapieinfected animals and human prion diseases [15]. ULK1, an autophagy protein, is necessary for cell survival during nutrient deficiency and is phosphorylated by AMPK [16].

AMP-activated protein kinase (AMPK) has been considered as a therapeutic target for several neurodegenerative diseases [17]. AMPK plays an essential role in preserving energy balance by phosphorylating and subsequently inactivating key enzymes involved in various biosynthetic pathways [18-20]. AMPK functions as a protein kinase that senses metabolic stress due to ATP depletion [21]. AMPK can be activated through phosphorylation by a tumor suppressor kinase, LKB1, under energy-deficient conditions and by CaMKK- $\beta$ in response to depletion of intracellular calcium [22-24]. CaMKK activates AMPK in an AMP-independent manner and is itself activated by an increase in the intracellular calcium levels [25]. Thus, calcium might play an essential role in the activation of AMPK. Vitamin D3 improves the concentration of cytosolic calcium ions and generates autophagy flux [26, 27]. Maria et al. proposed an increase in the concentration of intracellular calcium induces autophagy flux, which is dependent on the autophagy-related genes (Atg) and CaMKK- $\beta$ [28].
Calcium ions $\left(\mathrm{Ca}^{2+}\right)$ are secondary messengers that play important roles in various signal transduction processes [29]. In healthy neurons, $\mathrm{Ca}^{2+}$-related cascades control numerous cellular functions, including gene transcription, exocytosis, intracellular respiration, and membrane trafficking [30]. Perturbation of calciumregulating mechanisms results in extreme intracellular $\mathrm{Ca}^{2+}$, thereby triggering cell death [31]. Several reports suggest that $\operatorname{PrP}(106-126)$ alters calcium homeostasis through L-type calcium channels impairment [32, 33]. However, the molecular mechanisms regulating apoptosis during prion-mediated calcium influx remains largely unexplored.

Our previous study showed that prion proteinmediated neuronal cell death is triggered by the autophagy flux [34]. However, the relationship between intracellular calcium levels, AMPK activity, and autophagy flux has not been described yet. This study is focused on the effect of the changes in intracellular calcium levels on AMPK/autophagy flux pathway and PrP (106-126)-induced neurotoxicity. Our results suggest that preventing the calcium entry into the neurons affect AMPK/autophagy flux pathway and attenuates prion protein-mediated neurotoxicity. These outcomes suggest that regulating intracellular calcium levels, AMPK activity, and autophagy flux may be a practical therapeutic approach for neurodegenerative disorders including prion disease.

\section{Methods}

\section{Cell culture}

The primary murine cortex neuronal cells were prepared from embryonic 18-day ICR mice. Briefly, the brain was dissected in Hanks Buffered Saline Solution without $\mathrm{Mg}^{2+}$ and $\mathrm{Ca}^{2+}$ (HBSS: GIBCO, Grand Island, NY, USA), and digested in $0.25 \%$ trypsin containing DNAse I (2000 Units/mg) (GIBCO, Carlsbad, CA, USA) for $30 \mathrm{~min}$ at $37^{\circ} \mathrm{C}$. The obtained cell was diluted in fetal bovine serum (FBS), and cultured with Neuro basal media containing B-27 in tissue culture flasks coated with $50 \mu \mathrm{g} / \mathrm{ml}$ poly-Dlysine at a density of $3-4 \times 10^{5}$ cells $/ \mathrm{cm}^{2}$. Human neuroblastoma cell line SK-N-SH was obtained from the American Type Culture Collection (ATCC, Rockville, MD, USA). SK-N-SH cells were cultured in Minimum Essential Medium (Hyclone Laboratories, Logan, UT, USA) containing 10\% FBS (GIBCO, Grand Island, NY, USA) and gentamycin $(0.1 \mathrm{mg} / \mathrm{mL})$ in a humidified incubator at $37{ }^{\circ} \mathrm{C}$ with $5 \% \mathrm{CO}_{2}$. SK-N-SH (human neuroblastoma cell line, passage no.14) was acquired from the American Type Culture Collection (ATCC, Rockville, MD, USA). 


\section{PrP (106-126) treatment}

Synthetic prion peptides PrP (106-126) (sequence, LysThr-Asn-Met-Lys-His-Met-Ala-Gly-Ala-Ala-Ala-Ala-Gl y-Ala-Val-Val-Gly-Gly-Leu-Gly) were synthesized by Peptron (Seoul, Korea). The peptides were dissolved in sterile dimethyl sulfoxide (DMSO) at a concentration of $10 \mathrm{mM}$ (stock) and stored at $-20^{\circ} \mathrm{C}$.

\section{Annexin V assay}

Cells in the logarithmic phase were collected and cultured in 24-well plate at $4 \times 10^{4}$ cells/well. Cell survival was evaluated using an annexin $\mathrm{V}$ Assay kit (Santa Cruz Biotechnology, CA, USA) following to the manufacturer's procedure. The fluorescence was determined at 488-nm excitation and 525/30 emission using a Guava EasyCyte HT System (Millipore, Bedford, MA, USA).

\section{Lactate dehydrogenase assay}

Cytotoxicity was measured by evaluating the levels of lactate dehydrogenase in the cell culture supernatant using the lactate dehydrogenase (LDH) detection kit (Takara Bio, Inc., Tokyo, Japan) following the manufacturer's protocol. LDH activity was detected by measuring absorbance at $490 \mathrm{~nm}$ using a microplate reader (Spectra Max M2, Molecular Devices, Sunnyvale, CA, USA).

\section{BacMam transduction}

GFP-tagged wild-type or mutant LC3B was overexpressed in neuronal cells via viral transduction using Premo Autophagy Sensor LC3B-GFP (BacMam 2.0) kit (Life Technologies, P36235). Briefly, LC3B-FP or LC3B (G120A)-FP viral particles $(\mathrm{MOI}=30)$ were added to the growth medium and autophagosomes dynamics were visualized using fluorescence microscopy. The mutant LC3B (G120A)-FP was used as negative control.

\section{Immunocytochemistry}

Cells in the logarithmic phase were collected and cultured in $1 \%$ gelatin-coated cover-slit (12 mm; Nalge Nunc International, Naperville, IL) in 24-well plate at $4 \times 10^{4}$ cells/well. After treatment, fixed with $4 \%$ PFA in Phosphate Buffered Saline for $20 \mathrm{~min}$ at room temperature (RT). Cells were washed in sterilized TrisBuffered Saline with 0.1\% Tween 20 (TBST) for $10 \mathrm{~min}$, then blocked for $15 \mathrm{~min}$ in TBST with 5\% FBS, and then incubated for $3 \mathrm{~h}$ at RT with the primary antibodies (anti-phospho-AMPK $\alpha$ diluted 1:100; \#2535, Cell Signaling Technology) diluted with in TBST with 5\% FBS. Alexa Fluor 488-labeled donkey anti-rabbit IgG antibody (Molecular Probes, A21206) diluted 1:1000 was employed to visualize channel expression using fluorescence microscopy (Nikon Eclipse 80i). Image was evaluated using the NIS-Elements F ver4.60 Imaging software.

\section{Confocal microscopy}

For confocal microscopy, the cells were cultured on coverslips. After treatment, the cells were fixed with $4 \%$ PFA (in PBS) for $20 \mathrm{~min}$ at room temperature (RT) and permeabilized using $0.3 \%$ Triton X-100 (in PBS) with 5\% horse serum for $10 \mathrm{~min}$. Subsequent incubations were performed in permeabilization buffer. The cells were incubated with primary antibodies for $60 \mathrm{~min}$ at RT, washed four times with PBS and incubated with Alexa Fluor 488, Alexa Fluor 568, and Alexa Fluor 647 conjugated secondary antibodies at a concentration of $0.3 \mu \mathrm{g} /$ $\mathrm{ml}$ each for $60 \mathrm{~min}$ at RT. The coverslips were placed in mounting medium and imaged on a Zeiss LSM710 microscope equipped with a standard set of lasers through a $63 \times$ oil objective. Excitation wavelengths were 488, 543, and $633 \mathrm{~nm}$. Bandpass filters were set at 500550 (Alexa Fluor 488), 560-615 nm (Cy3, Alexa Fluor 568) and 650-750 nm (Alexa Fluor 647). Image acquisition was accomplished at the 12-bit rate. Settings were optimized to ensure suitable dynamic range, low background, and appropriate signal/noise ratio.

\section{Measurement of $\mathrm{Ca}^{2+}$ ions}

Neuronal cells cultured on collagen-coated confocal dishes were incubated with $5 \mu \mathrm{M}$ Fluo-4 AM (Invitrogen, Thermo Fisher Scientific) in culture media containing $1 \% \mathrm{FBS}$ at $37^{\circ} \mathrm{C}$ for $40 \mathrm{~min}$. The cells were washed three times with HBSS (Hank's Balanced Salt Solution). Intracellular calcium dynamics were visualized using a confocal microscope (Zeiss) with $488 \mathrm{~nm}$ excitation and 530 $\mathrm{nm}$ emission. For $\left[\mathrm{Ca}^{2+}\right] i$ calculation, the method of Tsien et al. [35] was employed with the following equation: $\left[\mathrm{Ca}^{2+}\right] i=\mathrm{Kd}(\mathrm{F}-\mathrm{Fmin}) /(\mathrm{Fmax}-\mathrm{F})$, where $\mathrm{Kd}$ is $345 \mathrm{nM}$ for Fluo-4, and $\mathrm{F}$ is the observed fluorescence level. Each tracing was calibrated for the maximal (Fmax) by adding ionomycin $(2 \mu \mathrm{M})$ and for the minimum intensity (Fmin) by adding EGTA $(5 \mathrm{mM})$ at the end of each measurement.

\section{Western blot analysis}

Cells in the logarithmic phase were collected and cultured in 6-well plate at $3 \times 10^{5}$ cells/well. After treatments, cells were washed with PBS and lysed in lysis buffer [25 mM HEPES (4-(2-hydroxyethyl)-1-piperazineethanesulfonic acid), pH 7.4, $100 \mathrm{mM} \mathrm{NaCl}, 1 \mathrm{mM}$ ethylene diamine tetra acetic acid (EDTA), $5 \mathrm{mM} \mathrm{MgCl}_{2}$, $0.1 \mathrm{mM}$ dithiothreitol (DTT), and a protease inhibitor mixture]. Equal quantities of cellular proteins (more than $15 \mu \mathrm{g} / \mu \mathrm{l}$ ) were electrophoretically resolved on a $10 \%$ sodium dodecyl sulfate (SDS) poly-acrylamide gel and transferred to a nitrocellulose membrane. Immunoreactivity was detected through consecutive incubation with blocking solution using $5 \%$ skim milk and primary antibodies, followed by the corresponding horseradish 

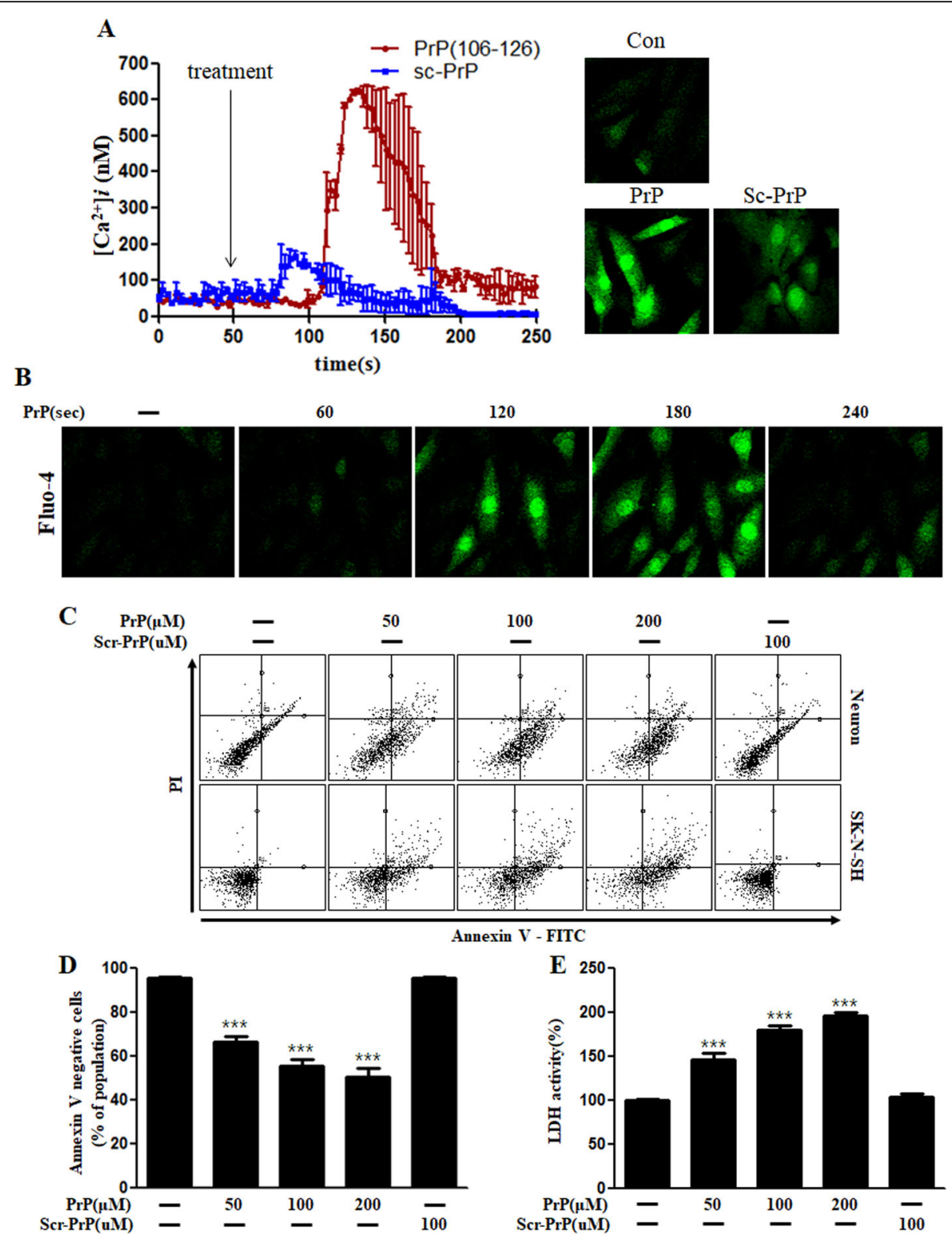

Fig. 1 PrP (106-126) increased the intracellular $\mathrm{Ca}^{2+}$ levels and induced apoptosis in neurons. a Neuroblastoma cells (SK-N-SH) were exposed to fluo-4 AM and the changes in the intracellular $\mathrm{Ca}^{2+}$ levels were evaluated using confocal microscopy. The time point of PrP (106-126) or scrambled-PrP (106-126) treatments $(100 \mu \mathrm{M})$ is shown by arrows. $\left[\mathrm{Ca}^{2+}\right]$ i was measured at $200 \mathrm{~s}$ after the treatment in three independent experiments, indicate that, average kinetics of $\mathrm{Ca}^{2+}$ in the PrP groups more than the sc-PrP groups. Data are represented as mean \pm SEM. $\mathbf{b}$ Green fluorescence (fluo-4) intensity that represents intracellular calcium concentration, changes time-dependently in SK-N-SH cells. c Primary neurons and SK-N-SH cells were exposed to different doses PrP (106-126) for $24 \mathrm{~h}$. Cell viability was determined by Annexin V assay using FITC-annexin V, which binds to phosphatidylserine of the plasma membrane during the apoptotic process. $\mathbf{d}$ The bar graph represents the average number of annexin $\mathrm{V}$ negative cells. e LDH (lactate dehydrogenase) assay was performed to measure the LDH released into the culture medium. The results represent at least three independent experiments. Data are expressed as the mean \pm SEM. ${ }^{* * *} p<0.001$, compared to control (one-way ANOVA). PrP, Prion peptide (106-126); sc-PrP, scrambled Prion peptide

peroxidase-conjugated secondary antibodies, and finally developed using enhanced chemi-luminescence substances i.e. west save gold detection kit (LF-QC0103, AbFrontier Inc.). The primary antibodies that antiphospho-AMPK $\alpha$ diluted 1:1000 (\#2535, Cell Signaling Technology), anti-AMPK $\alpha$ diluted 1:1000 (\#2532, Cell
Signaling Technology), anti-LC3B diluted 1:1000 (\#4108, Cell Signaling Technology), anti-P62 diluted 1:1000 (\#5114, Cell Signaling Technology) and anti- $\beta$-actin diluted 1:5000 (A5441, Sigma Aldrich) using antibody solution ( $1 \%$ skim milk in TBST) were used for immunoblotting. Images were inspected using a Fusion 

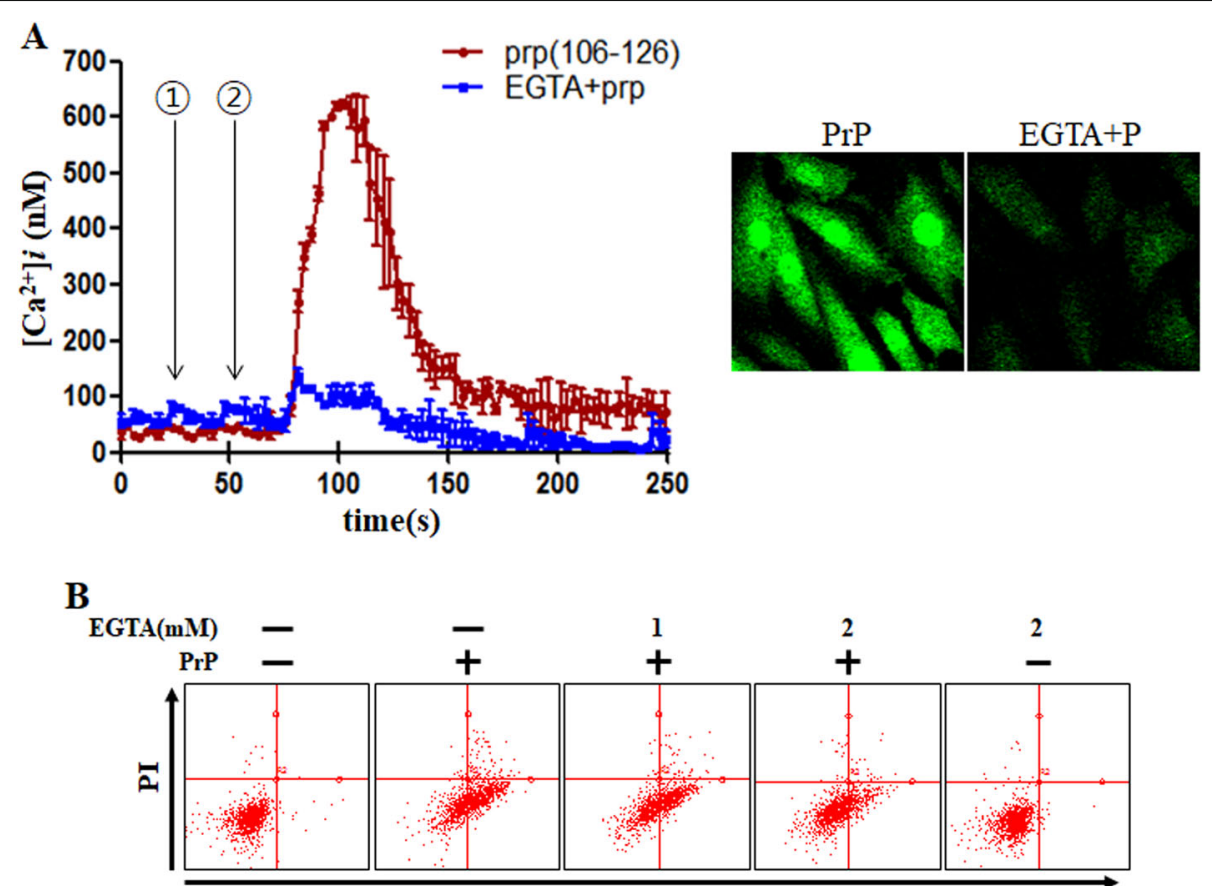

Annexin V - FITC

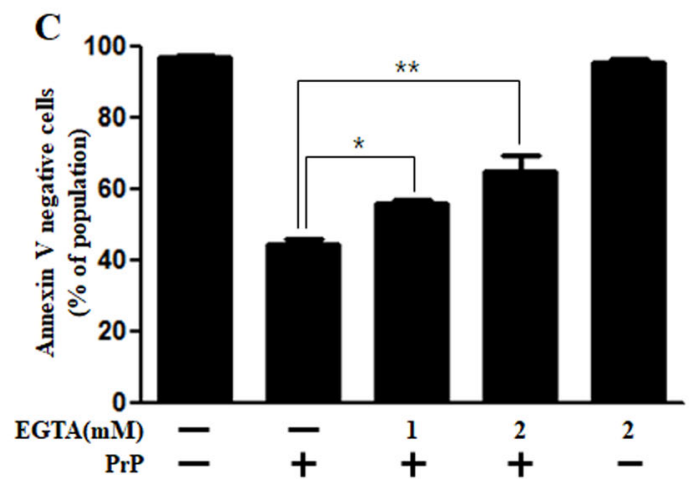

Fig. 2 PrP (106-126)-mediated increase in the intracellular $\mathrm{Ca}^{2+}$ induced neuronal apoptosis. a SK-N-SH cells were treated with fluo-4 AM and the change in $\mathrm{Ca}^{2+}$ levels was measured using confocal microscopy. The time point of EGTA treatment $(2 \mathrm{mM})$ is shown by the (1) arrow and $\operatorname{PrP}$ (106-126) treatment $(100 \mu \mathrm{M})$ is shown by the (2) arrow. Data are represented as mean $\pm \mathrm{SEM}$. [Ca $\left.{ }^{2+}\right]$ i was measured at $200 \mathrm{~s}$ after the treatment in three independent experiments. b SK-N-SH cells were incubated with EGTA (a calcium chelator) for $1 \mathrm{~h}$ and then treated with $100 \mu \mathrm{M}$ PrP (106-126) for $24 \mathrm{~h}$. Cell viability was evaluated using FITC-annexin V, indicate that EGTA decreased PrP-mediated neurotoxicity. c The bar graph represents the average number of annexin $\vee$ negative cells. The results represent at least three independent experiments. Data are expressed as the mean \pm SEM. ${ }^{*} p<0.05,{ }^{* *} p<0.01$, compared to the PrP-treated group (one-way ANOVA). PrP, Prion peptide (106-126); EGTA, Egtazic acid

FX7 imaging system (Vilber Lourmat, Torcy Z.I. Sud, France). Densitometry of the signal bands was evaluated using the Bio-1D software (Vilber Lourmat, Marne La Vallee, France).

\section{TEM (transmission electron microscopy) analysis}

Cells were fixed in 2\% glutaraldehyde (Electron Microscopy Sciences, Hatfield, PA, USA) and $2 \%$ paraformaldehyde (EMS, USA) in $0.05 \mathrm{M}$ sodium cacodylate (pH 7.2; Electron Microscopy Sciences) for $2 \mathrm{~h}$ at $4{ }^{\circ} \mathrm{C}$. After, the samples were fixed in $1 \%$ osmium tetroxide (Electron
Microscopy Sciences) for $1 \mathrm{~h}$ at $4{ }^{\circ} \mathrm{C}$, dehydrated by incubating in alcohol solutions of increasing concentration $(25,50,70,90$ and $100 \%)$ for 5 min each and entrenched in epoxy resin (Embed 812; Electron Microscopy Sciences) for $48 \mathrm{~h}$ at $60{ }^{\circ} \mathrm{C}$ following the manufacturers' instructions. Ultrathin sections $(60 \mathrm{~nm})$ were cut using the LKB-III ultratome (Leica Microsystems $\mathrm{GmbH}$, Wetzlar, Germany) and stained using 0.5\% uranyl acetate (Electron Microscopy Sciences) for $20 \mathrm{~min}$ and $0.1 \%$ lead citrate (Electron Microscopy Sciences) for $7 \mathrm{~min}$ at room temperature. Images were captured on a Hitachi H7650 

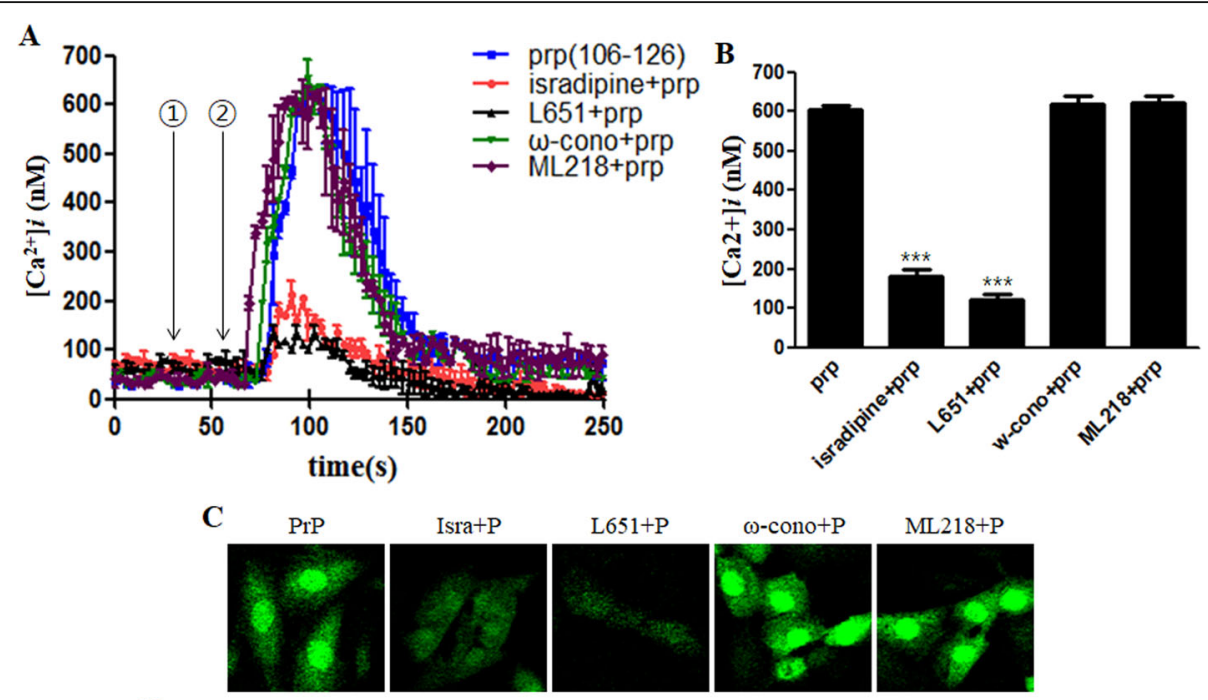

D

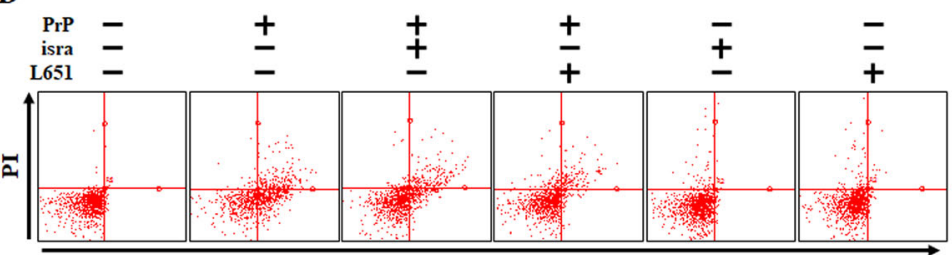

Annexin V - FITC
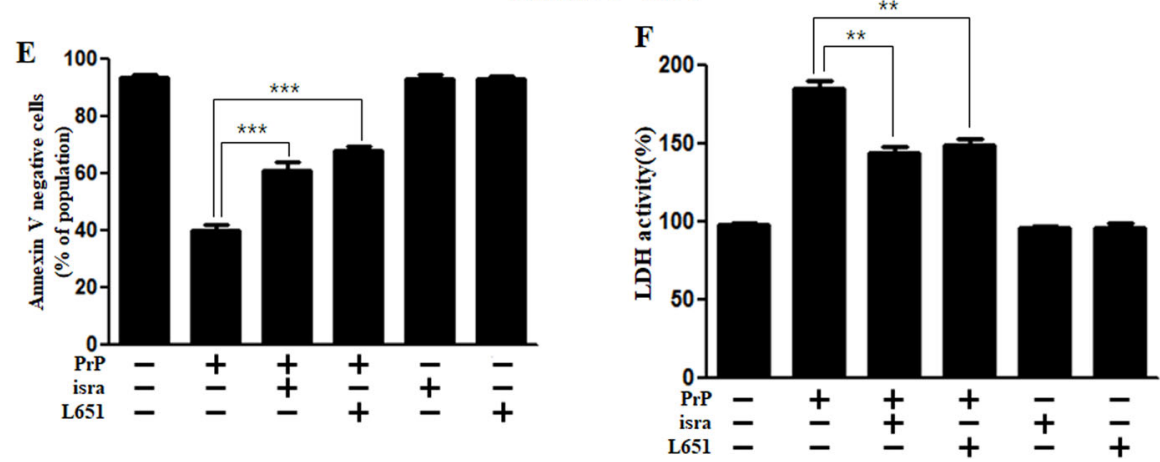

Fig. 3 PrP (106-126)-mediated increase in intracellular $\mathrm{Ca}^{2+}$ occurs via L-type calcium channel. a SK-N-SH cells were exposed to fluo-4 AM and the alterations in $\mathrm{Ca}^{2+}$ levels were evaluated using confocal microscopy. The time point of isradipine $(10 \mu \mathrm{M}), \mathrm{L} 651,582(20 \mu \mathrm{M})(\mathrm{L}$-type calcium channel blocker), $\omega$-conotoxin GVIA (20 nM) (T-type calcium channel blocker) or ML218 (2 $\mu \mathrm{M})$ ( $\mathrm{N}$-type calcium channel blocker) treatments is designated by the (1) arrow and $100 \mu \mathrm{M}$ of PrP (106-126) treatment is indicated by the (2) arrow. Data are represented as mean \pm SEM. [Ca ${ }^{2+}$ ] was measured at $200 \mathrm{~s}$ after the treatment in three independent experiments. $\mathbf{b}$ The bar graph represents the average of the peak value of calcium levels. c Green fluorescence (fluo-4) intensity represents intracellular calcium concentration in SK-N-SH cells using confocal microscopy, indicate that L-type calcium channel blockers decreased PrP-mediated $\mathrm{Ca}^{2+}$ influx. d SK-N-SH cells were incubated with isradipine or L651,582 for $1 \mathrm{~h}$ and then exposed to PrP (106-126) (100 $\mu \mathrm{M})$ for $24 \mathrm{~h}$. Cell viability was assessed by annexin $\mathrm{V}$ assay using FITC-annexin $\mathrm{V}$, indicate that isradipine and L651,582 decreased PrP-mediated neurotoxicity. e The bar graph represents the average number of annexin $\vee$ negative cells. $\mathbf{f} L D H$ assay was performed to measure LDH released into the medium. Annexin $V$ assay and LDH assay results represent at least three independent experiments. Data are expressed as the mean \pm SEM. ${ }^{* *} p<0.01,{ }^{* * *} p<0.001$; significant differences between each treatment group (Welch's Ttest). PrP, Prion peptide (106-126); isra, isradipine; $\omega$-cono, $\omega$-conotoxin GVIA

electron microscope (Hitachi, Ltd., Tokyo, Japan; magnification, 10,000x) at the Center for University-Wide Research Facilities (CURF), Chonbuk National University.

\section{Statistical analysis}

Results are presented as the mean of replicas \pm SEM. The Welch's correction was employed for comparing two samples. The one-way ANOVA followed by the Tukey post-hoc test was applied for comparing multiple samples. All statistical analyses were implemented with GraphPad Prism version 5.0 software. $\mathrm{P}$ values such as $* p<0.05$, ** $p<0.01$ or *** $p<0.001$ were considered statistically significant. 


\section{Results}

Prion peptide increases intracellular $\mathrm{Ca}^{2+}$ and induces neuronal cell death

We examined the role of prion peptide on intracellular $\mathrm{Ca}^{2+}$ levels in neuroblastoma (SK-N-SH) cells. PrP (106-126) treatment rapidly increased the intracellular $\mathrm{Ca}^{2+}$ levels in the cultured cells, although the increase was transient (Fig. 1a, b). Treatment with scrambled prion peptide showed a small increase in the intracellular $\mathrm{Ca}^{2+}$ level compared to prion peptide treatment. We investigated whether prion peptide induces neuronal apoptosis using Annexin V assay. PrP (106-126) exposure to both cultured primary neuronal cells as well as a neuroblastoma cell line (SK-N-SH) for $24 \mathrm{~h}$ resulted in cell death (Fig. 1c, d), whereas scrambled PrP (106-126) treatment did not induce neuronal cell death. Consistent with this, the amount of $\mathrm{LDH}$ released in the culture medium increased dose-dependently in PrP treated cells; scrambled PrP treated cells showed no change (Fig. 1e). These results show that prion peptide (106-126) treatment increases intracellular calcium levels and induces neutotoxicity.

\section{Prion peptide promotes neuronal apoptosis by calcium influx through L-type calcium channels}

Studies suggest that prion peptide increases the intracellular calcium levels in several cell types [36-38]. Using EGTA, a useful calcium chelating agent in media, we investigated whether $\operatorname{PrP}$ (106-126)-mediated intracellular calcium increase is due to external influx or internal release from ER or mitochondria.
Our results confirmed that the calcium present in the culture medium was taken up by the PrP (106-126) treated cells leading to an increase in the intracellular calcium since EGTA treatment repressed PrP (106126)-mediated calcium increase (Fig. 2a) and neuronal apoptosis (Fig. 2b, c).

Silei et al. showed that L-type calcium channels are involved in this process [39]. We investigated the calcium channels involved in this process using various calcium channel blockers. We found that that treatment with isradipine and L651,582 the L-type calcium channel blockers obstructed the PrP-induced calcium increase (Fig. 3a, b). Fluorescence experiments also revealed that L-type calcium channel blockers repressed intracellular calcium increase (Fig. 3c). Moreover, the L-type calcium channel blockers attenuated prion peptide-induced neuronal apoptosis and $\mathrm{LDH}$ release (Fig. 3d, e, f). These results suggest that prion peptide-mediated increase in the intracellular calcium and neuronal cell death is via L-type calcium channels.

\section{Prion peptide induced neuronal apoptosis via AMPK down-regulation}

We observed that AMPK is involved in PrP (106-126)mediated neuronal apoptosis. PrP (106-126) treatment inhibited AMPK phosphorylation in a dose-dependent manner (Fig. 4a, b) as assessed by immunohistochemistry (Fig. 4c, d). AMPK agonist, AICAR, increased the AMPK phosphorylation in the prion peptide treated cells (Fig. 5a, b). Further, AICAR treatment ameliorated PrP
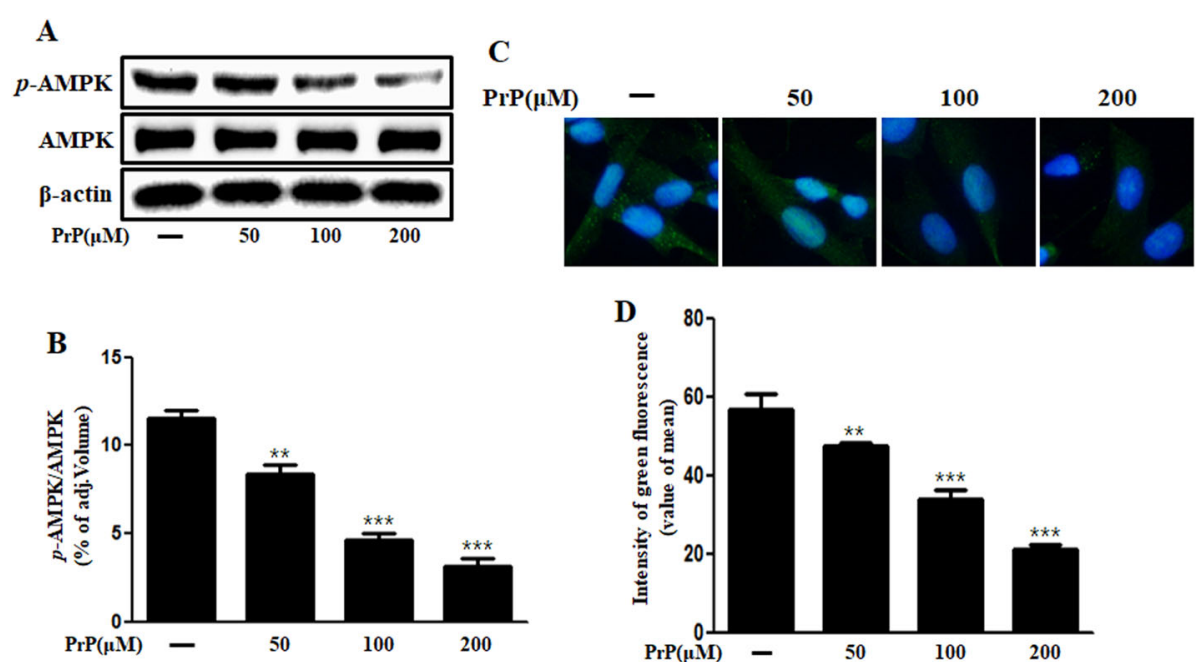

Fig. 4 Prion peptide (106-126) treatment suppressed AMPK phosphorylation in neuronal cells. a Primary neurons were incubated with 50, 100, and $200 \mu \mathrm{M}$ of PrP (106-126) for $6 \mathrm{~h}$. Phospho-AMPK levels were analyzed by western blot analysis, indicate that PrP decreased AMPK phosphorylation. $\mathbf{b}$ Bar graph represents the mean levels of phospho-AMPK. c Immunocytochemistry to detect phospho-AMPK in SK-N-SH cells. $\mathbf{d}$ The bar graph represents the mean green fluorescence intensity. Results represent at least three independent experiments. Data are expressed as the mean \pm SEM. ${ }^{* *} p<0.01,{ }^{* * *} p<0.001$, compared to control (one-way ANOVA). PrP, Prion peptide (106-126); adj.volume, adjustment of volume (band volume minus background volume) 


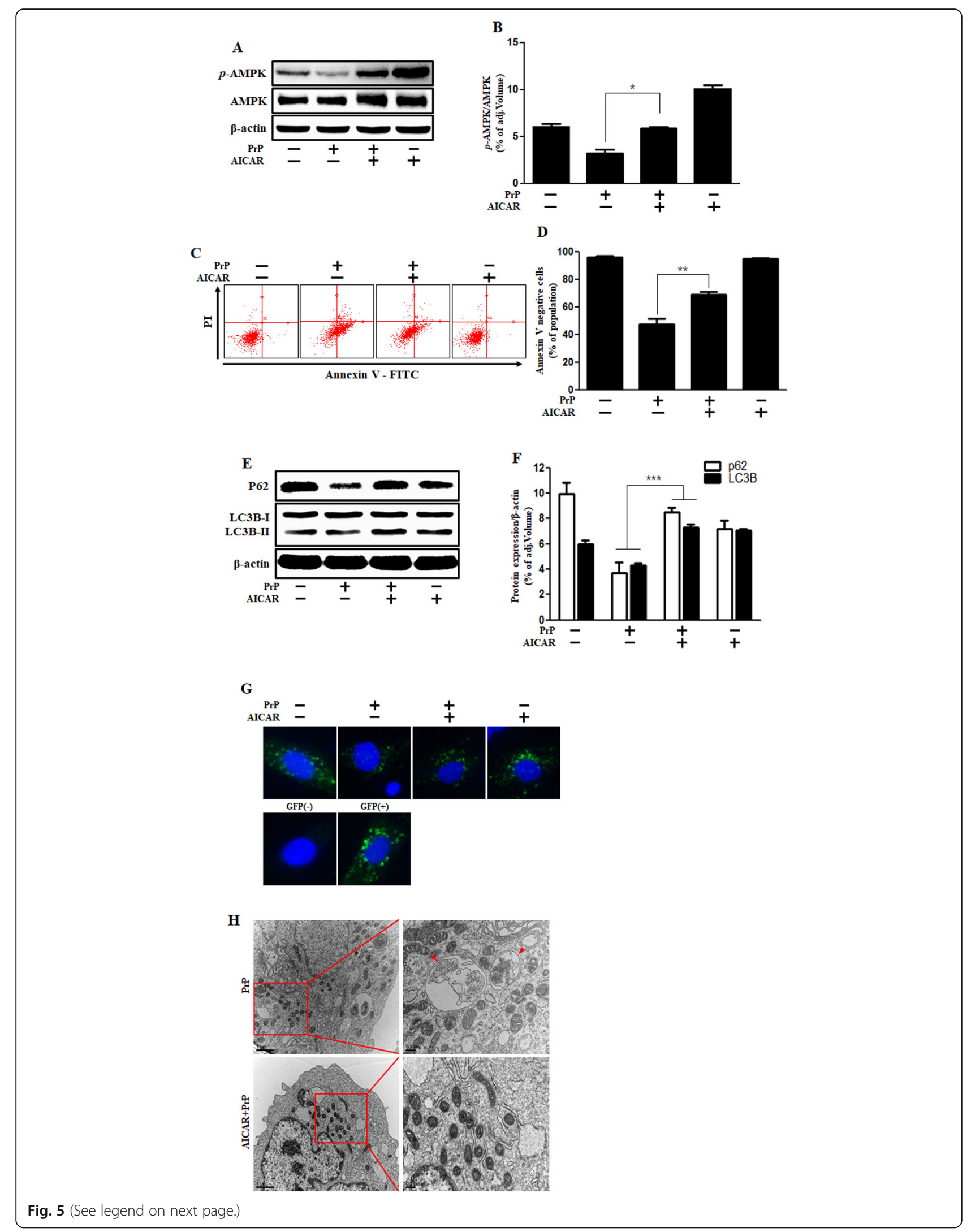


(See figure on previous page.)

Fig. 5 AMPK activator alleviates PrP (106-126)-induced autophagy flux and neurotoxicity. a Primary neuronal cells were incubated with AMPK activator (AICAR) for $1 \mathrm{~h}$ and then exposed to PrP (106-126) (100 $\mu \mathrm{M})$ for $6 \mathrm{~h}$. The cells were evaluated for $p$-AMPK levels by western blot analysis, indicate that AICAR increased p-AMPK. $\mathbf{b}$ The bar graph represents the average $\mathrm{p}$-AMPK levels. $\mathbf{c}$ SK-N-SH cells were incubated with AICAR for $1 \mathrm{~h}$ and then treated to $100 \mu \mathrm{M}$ of PrP (106-126) for $24 \mathrm{~h}$. Cell viability was assessed by annexin $\mathrm{V}$ assay. $\mathbf{d}$ The bar graph represents the mean number of annexin $V$ negative cells. e SK-N-SH cells were incubated with AICAR for $1 \mathrm{~h}$ and then exposed to PrP (106-126) (100 $\mu \mathrm{M})$ for $6 \mathrm{~h}$. P62 and LC3B expression were evaluated by western blot analysis, indicate that AICAR increased P62. $\mathbf{f}$ The bar graph represents the mean LC3B-II and p62 levels. g SK-N-SH cells were incubated GFP-LC3B virus (MOI 30) for over $18 \mathrm{~h}$ and then exposed to AICAR or PrP (106-126). Cell nuclei were stained with DAPI (blue) and evaluated by confocal microscopy. The cells were treated with negative and positive control reagent (CQ) at the same time. $\mathbf{h}$ SK-N-SH cells were incubated with AICAR for $1 \mathrm{~h}$ and then exposed to PrP (106-126) (100 $\mu \mathrm{M})$ for $6 \mathrm{~h}$. Autophagy flux mediated by AICAR and PrP (106-126) was analyzed by TEM. Arrowheads designate autophagosomes and autolysosomes. Western blot, Annexin V assay, and GFP-LC3B puncta formation assay results represent at least three independent experiments and TEM represents two independent experiments. Data are expressed as the mean \pm SEM. ${ }^{* *} p<0.01,{ }^{* * *} p<0.001$; significant differences between each treatment group (Welch's Ttest). PrP, Prion peptide (106-126); GFP (+), Positive control; GFP (-), Negative control; adj.volume, adjustment of volume (band volume minus background volume)

(106-126)-induced neuronal toxicity (Fig. 5c, d). In a previous study, we demonstrated that prion peptide generates autophagic flux in neuronal cells [34]. We examined the role of AMPK on prion peptide-mediated autophagy flux and found that AICAR treatment alleviated the prion peptide-induced autophagy flux activation (Fig. 5e, f). Furthermore, the GFP-LC3B puncta formation assay and TEM analysis verified the AICAR inhibited PrP (106-126)-induced autophagy flux activation (Fig. 5g, h). Altogether, our results show that prion peptide-mediated autophagy flux activation and neuronal apoptosis is regulated by AMPK. It also confirms that AMPK activation alleviates prion peptideinduced neuronal cell death through autophagy flux inhibition.

\section{L-type calcium channel blocker attenuated the prion peptide-mediated autophagy flux and phospho-AMPK reduction}

To investigate the effect of prion peptide-mediated changes in intracellular calcium levels on AMPK signaling and autophagy flux, we employed L651,582 an L-type calcium channel blocker. We found that L651, 582 treatment improved the AMPK activity in PrPtreated neurons by western blot analysis (Fig. 6a, b) and immunocytochemistry (Fig. 6c, d). Further, L651,582 repressed the prion peptide-induced autophagy flux activation as assessed by western blot analysis (Fig. 6e, f) and immunocytochemistry (Fig. 6g). These results demonstrated that prion peptide-mediated suppression of AMPK activity and induction of autophagy flux are dependent on intracellular calcium levels. In conclusion, our results suggest that prion peptide changes intracellular calcium levels and autophagy flux through AMPK signaling in neuronal cells.

\section{Discussion}

The role of autophagy in pathological process is under debate: inhibition of autophagy has been reported to have both beneficial and harmful effects for neurons [40-42]. autophagy has been recognized recently as a possible deleterious event as well. Activation of autophagic signaling was observed in ischemic brain [43], mediating ischemic neuronal death [44]. Jihoon et al. showed that autophagy flux in neurons is activated by amyloid $\beta$ [45]. In previous study, we interpreted human prion peptide stimulates acute autophagy flux as autophagic cell death in neurons [34]. In our results, PrP (106-126) treatment induced LC3-II decrease and p62 decrease. This results could indicate autophagy flux inhibition. But we suggested the decrease of LC3-II and p62 are consequence of acute autophagy flux. Decreased p62/ SQSTM1 levels are associated with autophagy activation and lysosomal degradation [46] and LC3-II is decreased after longer periods of autophagy activation [47]. After conducting other experiments such as GFP-LC3 puncta assay, TEM, ICC, we interpreted PrP (106-126) activates autophagy flux as autophagic cell death in neurons. There is another evidence that autophagy inhibitor (CQ) attenuated PrP (106-126)-induced autophagic cell death.

It is well known that AMPK and autophagy flux are the metabolic and cellular homeostasis regulators that are activated during starvation [48-50]. It has been well known that AMPK activation could trigger autophagy flux [51, 52]. However, our present study shows that prion peptide decreases AMPK phosphorylation while increases autophagic cell death (Fig. 5). We propose that prion peptide could cause AMPK dysfunction and induce autophagic cell death. The role of AMPK and autophagy flux in neurodegeneration remains unclear so that further studies are required.

Calcium plays a pivotal role in controlling the fate of neurons and targeting calcium channels might be a strategy for treating patients with neurodegenerative diseases [53]. Some studies showed that PrP (106-126)mediated alteration in ER $\mathrm{Ca}^{2+}$ homeostasis is responsible for the increase in the cytosolic $\mathrm{Ca}^{2+}$ concentration, leading to caspase-3 activation, cytochrome $c$ release, 


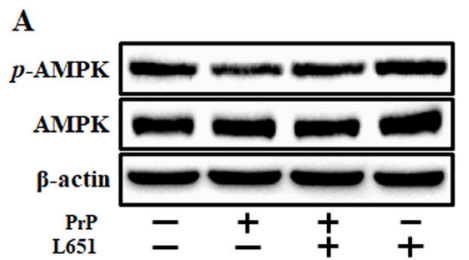

B

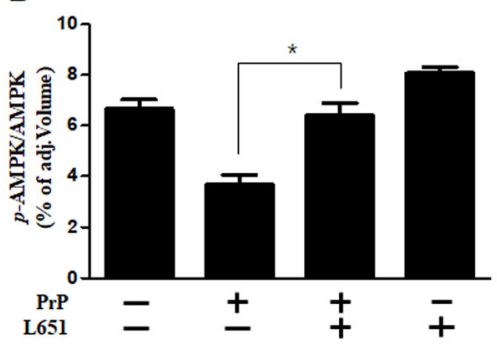

C

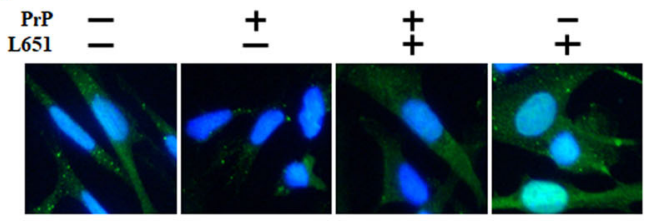

D

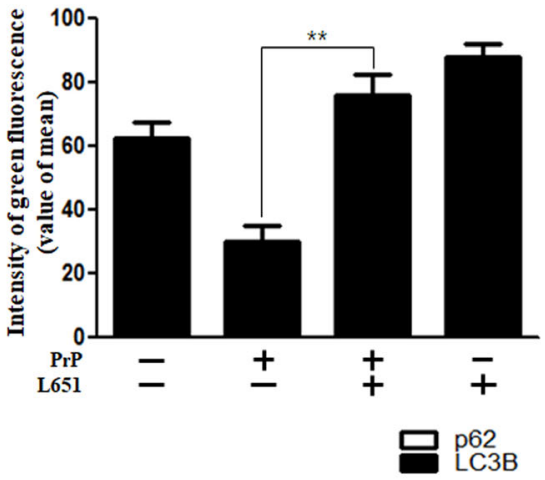

F

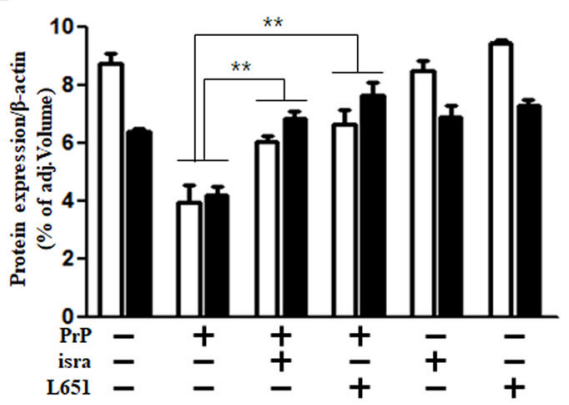

G

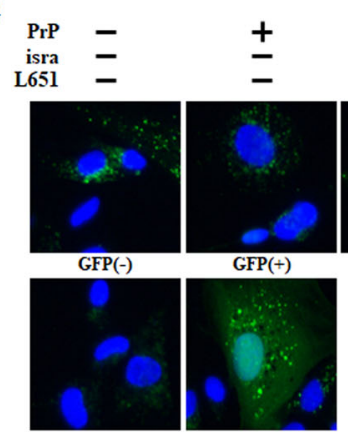

Fig. 6 L-type calcium channel blocker reversed PrP (106-126)-mediated reduction in AMPK activity and increased autophagy flux in neuronal cells. a The primary neuronal cells were incubated with $L 651,582$ for $1 \mathrm{~h}$ and then exposed to PrP (106-126) (100 $\mu \mathrm{M})$ for $6 \mathrm{~h}$. The treated cells were evaluated for $p$-AMPK by western blot analysis, indicate that L651,582 increased p-AMPK. b The bar graph represents the mean p-AMPK levels. c Immunocytochemistry for the $p$-AMPK was performed in SK-N-SH cells. $\mathbf{d}$ The bar graph represents the mean green fluorescence intensity. e Primary neuronal cells were incubated with isradipine and L651,582 for $1 \mathrm{~h}$ and then treated with PrP (106-126) (100 $\mu \mathrm{M})$ for $6 \mathrm{~h}$. The cells were evaluated for P62 and LC3B expression by western blot analysis, indicate that isradipine and L651,582 increased p62. f The bar graph represents the mean p62 and LC3B-II levels. g SK-N-SH cells were treated with GFP-LC3B virus for over $18 \mathrm{~h}$ and then exposed to PrP (106-126) for $6 \mathrm{~h}$ with isradipine or L651,582. Cell nuclei were stained with DAPI (blue) and evaluated by confocal microscopy. The cells were treated with negative and positive control reagent (CQ) at the same time. Western blot, immunocytochemistry, and GFP-LC3B puncta formation assay results represent at least three independent experiments. Data are expressed as the mean $\pm \mathrm{SEM} .{ }^{*} p<0.05,{ }^{* *} p<0.01$; significant differences between each treatment group (Welch's T-test). PrP, Prion peptide (106-126); isra, isradipine; adj.volume, adjustment of volume (band volume minus background volume) 
and apoptosis [36, 54, 55]. However, other studies suggest that scrapie or prion peptide cause a reduction in cytosolic calcium levels through L-type calcium channels by depolarizing $\mathrm{K}^{+}$concentrations $[33,56,57]$. Jochen et al. claimed existence of PrPc is correlated with calcium influx through L-type calcium channels [58]. These inconsistent results may vary depending on the experimental method, condition or cell types. Although present studies suggest calcium ion as a secondary messenger, the experimental evidence for this has been very restricted. Various reports suggest that an increase in the intracellular $\mathrm{Ca}^{2+}$ levels stimulates autophagy flux via diverse signaling pathways such as mTOR, CaMKK, and AMPK $[22,24,28]$. We identified PrP (106-126) treatment triggered transitory rapid calcium influx, AMPK reduction and autophagic cell death through Ltype calcium channels. Further studies are required to prove the role of calcium-dependent signaling proteins such as calcineurin, CaMKK, etc. in regulating autophagy flux. We postulate that prion peptide could be a beneficial tool to develop novel therapeutic strategies for prion diseases. Since we only studied the effects of prion peptide in-vitro, the intracellular calcium variation and AMPK activity in prion disease is yet to be established in-vivo. Further in-vivo studies are required to conclusively prove that the involvement of calcium-dependent pathways in prion peptide-induced neuronal apoptosis.

\section{Conclusions}

Our results indicate that prion peptide increases intracellular calcium ion, resulting in decreased AMPK phosphorylation that stimulates autophagic cell death. Prion peptide causes an inflow of calcium ions through L-type calcium channels, which leads to neuronal injury through the AMPK/autophagic cell death signaling. Given that change in intracellular calcium levels, AMPK activity, and autophagy flux induce neurotoxicity, which has been observed in prion models, our results will improve the understanding of the prion disease pathogenesis and identifies L-type calcium channels as a potential therapeutic target.

\section{Abbreviations}

PrPsc: Scrapie isoform of the prion protein; PrPc: Normal prion protein; PrP: Prion protein; AMPK: AMP-activated protein kinase; CaMKK: Calmodulindependent protein kinase kinase; CNS: Central Nervous System; ULK1: Serine/ threonine kinase Unc-51-like kinase-1; ATP: Adenosine triphosphate; LKB1: Liver kinase B1; Atg: Autophagy; EGTA: Ethylene Glycol Tetraacetic Acid; LDH: Lactate dehydrogenase; AICAR: AMPK agonist 5-aminoimidazole-4-carboxamide ribonucleotide; TEM: Transmission electron microscopy; ER: Endoplasmic reticulum
}

\section{Acknowledgments}

This study was supported by National Research Foundation of the Korea Grant (NRF) which was funded by Ministry of Education

(2019R1A2B5B02069765).
Authors' contributions

JHM and SYP designed, executed the study, analyzed data, and wrote the manuscript. The authors read and approved the final manuscript.

\section{Funding}

Not applicable.

Availability of data and materials

All data generated or analyzed during this study are included in this published article.

Ethics approval and consent to participate

Ethical approval for the project was granted by the institutional review board of the Jeonbuk National University.

\section{Consent for publication}

Not applicable.

\section{Competing interests}

The authors declare that they have no competing interests.

Received: 13 February 2020 Accepted: 30 April 2020

Published online: 11 July 2020

\section{References}

1. Costanzo M, Zurzolo C. The cell biology of prion-like spread of protein aggregates: mechanisms and implication in neurodegeneration. Biochem J. 2013;452:1-17.

2. Sakudo A, Ano Y, Onodera T, Nitta K, Shintani H, Ikuta K, et al. Fundamentals of prions and their inactivation (review). Int J Mol Med. 2011;27:483-9.

3. Pan KM, Baldwin M, Nguyen J, Gasset M, Serban A, Groth D, et al. Conversion of alpha-helices into beta-sheets features in the formation of the scrapie prion proteins. Proc Natl Acad Sci U S A. 1993:90:10962-6.

4. Saa P, Harris DA, Cervenakova L. Mechanisms of prion-induced neurodegeneration. Expert Rev Mol Med. 2016;18:e5.

5. Brandner S, Isenmann S, Raeber A, Fischer M, Sailer A, Kobayashi Y, et al Normal host prion protein necessary for scrapie-induced neurotoxicity. Nature. 1996:379:339-43.

6. Forloni G, Angeretti N, Chiesa R, Monzani E, Salmona M, Bugiani O, et al. Neurotoxicity of a prion protein fragment. Nature. 1993;362:543-6.

7. Chiesa R, Harris DA. Prion diseases: what is the neurotoxic molecule? Neurobiol Dis. 2001;8:743-63.

8. Boellaard JW, Kao M, Schlote W, Diringer H. Neuronal autophagy in experimental scrapie. Acta Neuropathol. 1991;82:225-8.

9. Sikorska B, Liberski PP, Brown P. Neuronal autophagy and aggresomes constitute a consistent part of neurodegeneration in experimental scrapie. Folia Neuropathol. 2007:45:170-8.

10. Cuervo AM. Autophagy: in sickness and in health. Trends Cell Biol. 2004;14: 70-7.

11. Cuervo AM. Autophagy: many paths to the same end. Mol Cell Biochem. 2004;263:55-72

12. Goold R, McKinnon C, Rabbanian S, Collinge J, Schiavo G, Tabrizi SJ. Alternative fates of newly formed PrPSC upon prion conversion on the plasma membrane. J Cell Sci. 2013;126:3552-62.

13. Heiseke A, Aguib Y, Schatzl HM. Autophagy, prion infection and their mutual interactions. Curr Issues Mol Biol. 2010;12:87-97.

14. Yao H, Zhao D, Khan SH, Yang L. Role of autophagy in prion proteininduced neurodegenerative diseases. Acta Biochim Biophys Sin Shanghai. 2013:45:494-502.

15. Xu Y, Tian C, Wang SB, Xie WL, Guo Y, Zhang J, et al. Activation of the macroautophagic system in scrapie-infected experimental animals and human genetic prion diseases. Autophagy. 2012;8:1604-20.

16. Egan DF, Shackelford DB, Mihaylova MM, Gelino S, Kohnz RA, Mair W, et al. Phosphorylation of ULK1 (hATG1) by AMP-activated protein kinase connects energy sensing to mitophagy. Science. 2011;331:456-61.

17. $\mathrm{Ng} \mathrm{CH}$, Guan MS, Koh C, Ouyang X, Yu F, Tan EK, et al. AMP kinase activation mitigates dopaminergic dysfunction and mitochondrial abnormalities in drosophila models of Parkinson's disease. J Neurosci. 2012; 32:14311-7

18. Carling D. The AMP-activated protein kinase cascade--a unifying system for energy control. Trends Biochem Sci. 2004;29:18-24. 
19. Hardie DG, Carling D, Carlson M. The AMP-activated/SNF1 protein kinase subfamily: metabolic sensors of the eukaryotic cell? Annu Rev Biochem. 1998;67:821-55.

20. Kahn BB, Alquier T, Carling D, Hardie DG. AMP-activated protein kinase: ancient energy gauge provides clues to modern understanding of metabolism. Cell Metab. 2005;1:15-25.

21. Corton JM, Gillespie JG, Hardie DG. Role of the AMP-activated protein kinase in the cellular stress response. Curr Biol. 1994;4:315-24.

22. Hawley SA, Pan DA, Mustard KJ, Ross L, Bain J, Edelman AM, et al. Calmodulin-dependent protein kinase kinase-beta is an alternative upstream kinase for AMP-activated protein kinase. Cell Metab. 2005;2:9-19.

23. Shaw RJ, Bardeesy N, Manning BD, Lopez L, Kosmatka M, DePinho RA, et al. The LKB1 tumor suppressor negatively regulates mTOR signaling. Cancer Cell. 2004;6:91-9.

24. Woods A, Dickerson K, Heath R, Hong SP, Momcilovic M, Johnstone SR, et al. $\mathrm{Ca} 2+$ /calmodulin-dependent protein kinase kinase-beta acts upstream of AMP-activated protein kinase in mammalian cells. Cell Metab. 2005;2:21-33.

25. Park S, Scheffler TL, Rossie SS, Gerrard DE. AMPK activity is regulated by calcium-mediated protein phosphatase 2A activity. Cell Calcium. 2013;53: 217-23

26. Hoyer-Hansen M, Bastholm L, Mathiasen IS, Elling F, Jaattela M. Vitamin D analog EB1089 triggers dramatic lysosomal changes and Beclin 1-mediated autophagic cell death. Cell Death Differ. 2005;12:1297-309.

27. Mathiasen IS, Sergeev IN, Bastholm L, Elling F, Norman AW, Jaattela M. Calcium and calpain as key mediators of apoptosis-like death induced by vitamin D compounds in breast cancer cells. J Biol Chem. 2002;277:30738-45.

28. Hoyer-Hansen M, Bastholm L, Szyniarowski P, Campanella M, Szabadkai G, Farkas T, et al. Control of macroautophagy by calcium, calmodulindependent kinase kinase-beta, and BCl-2. Mol Cell. 2007;25:193-205.

29. Berridge MJ, Bootman MD, Lipp P. Calcium--a life and death signal. Nature 1998;395:645-8.

30. Berridge MJ, Lipp P, Bootman MD. Signal transduction. The calcium entry pas de deux. Science. 2000;287:1604-5.

31. Paschen W. Mechanisms of neuronal cell death: diverse roles of calcium in the various subcellular compartments. Cell Calcium. 2003;34:305-10.

32. Florio T, Thellung S, Amico C, Robello M, Salmona M, Bugiani O, et al. Prion protein fragment 106-126 induces apoptotic cell death and impairment of L-type voltage-sensitive calcium channel activity in the GH3 cell line. J Neurosci Res. 1998;54:341-52.

33. Thellung S, Florio T, Villa V, Corsaro A, Arena S, Amico C, et al. Apoptotic cell death and impairment of L-type voltage-sensitive calcium channel activity in rat cerebellar granule cells treated with the prion protein fragment 106126. Neurobiol Dis. 2000;7:299-309.

34. Moon JH, Lee JH, Nazim UM, Lee YJ, Seol JW, Eo SK, et al. Human prion protein-induced autophagy flux governs neuron cell damage in primary neuron cells. Oncotarget. 2016;7:29989-30002

35. Tsien RY, Pozzan T, Rink TJ. T-cell mitogens cause early changes in cytoplasmic free $\mathrm{Ca} 2+$ and membrane potential in lymphocytes. Nature. 1982;295:68-71.

36. Florio T, Grimaldi M, Scorziello A, Salmona M, Bugiani O, Tagliavini F, et al. Intracellular calcium rise through L-type calcium channels, as molecular mechanism for prion protein fragment 106-126-induced astroglial proliferation. Biochem Biophys Res Commun. 1996;228:397-405.

37. Herms JW, Madlung A, Brown DR, Kretzschmar HA. Increase of intracellular free Ca2+ in microglia activated by prion protein fragment. Glia. 1997;21:253-7.

38. Korotzer AR, Whittemore ER, Cotman CW. Differential regulation by betaamyloid peptides of intracellular free $\mathrm{Ca} 2+$ concentration in cultured rat microglia. Eur J Pharmacol. 1995;288:125-30.

39. Silei V, Fabrizi C, Venturini G, Salmona M, Bugiani O, Tagliavini F, et al. Activation of microglial cells by PrP and beta-amyloid fragments raises intracellular calcium through L-type voltage sensitive calcium channels. Brain Res. 1999:818:168-70

40. Baek SH, Noh AR, Kim KA, Akram M, Shin YJ, Kim ES, et al. Modulation of mitochondrial function and autophagy mediates carnosine neuroprotection against ischemic brain damage. Stroke. 2014;45:2438-43.

41. Knoferle J, Koch JC, Ostendorf T, Michel U, Planchamp V, Vutova P, et al. Mechanisms of acute axonal degeneration in the optic nerve in vivo. Proc Natl Acad Sci U S A. 2010;107:6064-9.

42. Wei K, Wang P, Miao C-Y. A double-edged sword with therapeutic potential: an updated role of autophagy in ischemic cerebral injury. CNS Neurosci Ther. 2012;18:879-86.
43. Tian F, Deguchi K, Yamashita T, Ohta Y, Morimoto N, Shang J, et al. In vivo imaging of autophagy in a mouse stroke model. Autophagy. 2010;6:1107-14

44. Rami A, Kogel D. Apoptosis meets autophagy-like cell death in the ischemic penumbra: two sides of the same coin? Autophagy. 2008:4:422-6.

45. Nah J, Pyo JO, Jung S, Yoo SM, Kam TI, Chang J, et al. BECN1/Beclin 1 is recruited into lipid rafts by prion to activate autophagy in response to amyloid beta 42. Autophagy. 2013;9:2009-21.

46. Klionsky DJ, Abdelmohsen K, Abe A, Abedin MJ, Abeliovich H, Acevedo Arozena $\mathrm{A}$, et al. Guidelines for the use and interpretation of assays for monitoring autophagy (3rd edition). Autophagy. 2016;12:1-222.

47. Mizushima N, Yoshimori T, Levine B. Methods in mammalian autophagy research. Cell. 2010;140:313-26.

48. Ha J, Guan KL, Kim J. AMPK and autophagy in glucose/glycogen metabolism. Mol Aspects Med. 2015;46:46-62.

49. Efeyan A, Zoncu R, Sabatini DM. Amino acids and mTORC1: from lysosomes to disease. Trends Mol Med. 2012;18:524-33.

50. Christian P, Sacco J, Adeli K. Autophagy: emerging roles in lipid homeostasis and metabolic control. Biochimica et Biophysica Acta (BBA) - Mol Cell Biol Lipids. 2013;1831:819-24.

51. Herzig S, Shaw RJ. AMPK: guardian of metabolism and mitochondrial homeostasis. Nat Rev Mol Cell Biol. 2018;19:121-35.

52. Mihaylova MM, Shaw RJ. The AMPK signalling pathway coordinates cell growth, autophagy and metabolism. Nat Cell Biol. 2011;13:1016-23.

53. Fairless R, Williams SK, Diem R. Dysfunction of neuronal calcium signalling in neuroinflammation and neurodegeneration. Cell Tissue Res. 2014;357:455-62.

54. O'Donovan CN, Tobin D, Cotter TG. Prion protein fragment PrP-(106-126) induces apoptosis via mitochondrial disruption in human neuronal SH-SY5Y cells. J Biol Chem. 2001;276:43516-23.

55. Ferreiro E, Resende R, Costa R, Oliveira CR, Pereira CM. An endoplasmicreticulum-specific apoptotic pathway is involved in prion and amyloid-beta peptides neurotoxicity. Neurobiol Dis. 2006;23:669-78.

56. Korte S, Vassallo N, Kramer ML, Kretzschmar HA, Herms J. Modulation of Ltype voltage-gated calcium channels by recombinant prion protein. J Neurochem. 2003;87:1037-42.

57. Sandberg MK, Wallen P, Wikstrom MA, Kristensson K. Scrapie-infected GT1-1 cells show impaired function of voltage-gated $\mathrm{N}$-type calcium channels (ca(v) 2.2) which is ameliorated by quinacrine treatment. Neurobiol Dis. 2004;15:143-51.

58. Herms JW, Korte S, Gall S, Schneider I, Dunker S, Kretzschmar HA. Altered intracellular calcium homeostasis in cerebellar granule cells of prion proteindeficient mice. J Neurochem. 2000;75:1487-92.

\section{Publisher's Note}

Springer Nature remains neutral with regard to jurisdictional claims in published maps and institutional affiliations.

\section{Ready to submit your research? Choose BMC and benefit from:}

- fast, convenient online submission

- thorough peer review by experienced researchers in your field

- rapid publication on acceptance

- support for research data, including large and complex data types

- gold Open Access which fosters wider collaboration and increased citations

- maximum visibility for your research: over $100 \mathrm{M}$ website views per year

At BMC, research is always in progress.

Learn more biomedcentral.com/submissions 